\title{
Indonesia dalam Pertautan Budaya Pembangunan dan Budaya Warga Desa
}

\author{
Ivanovich Agusta
}

ABSTRACT The construction of the next imagined-village as a part of the next imagined-
Indonesia evokes the need of a new genre on embedding the culture of development and the
culture of civil-village. The article presents an "Until-Where" genre (on where the aims of
development are reached). In the genre, praxis orientation becomes a context of both cultural
analysis and social structure. The deconstructive critique of the culture of development is
focused on Kantian humanism, evolutionism and development planning, the politics of space,
and capitalization on village development. Co-articulation between the culture of development (which has the tendency for uniformity) and the culture of civil-village (which has the tendency for variation) is constructed, firstly, on toleration between the stake-holders for social transformation. Then the article proposes "Praxis of Familiation", i.e. imagination on the family structure as a translation process for external influence. Focused on the lower stratum, the familiation should be used to empower the lowest one.

KEYWORDS deconstruction, "Until-Where" genre, "Praxis of Familiation"

Konsep "pembangunan" dalam tulisan ini sama dengan konsep "development" sebagai perubahan sosial yang terencana dari keadaan tradisional menuju keadaan modern. Di sini "Desa" dilihat sebagai satuan administrasi formal di bawah kecamatan. Kedua konsep tersebut tidak berbeda dari pengertian umum selama ini, sebagaimana dipraktikkan dalam pembangunan desa di Indonesia.

Terhadap kedua konsep tersebut, penulis ini berposisi untuk tidak mendukungnya! Sejalan dengan posisi penulis ini, makna "budaya" diarahkan secara lebih aktif sebagai alasan pelaku yang dipandangnya paling tepat untuk menjelaskan keadaan lingkungan sekitar. Alasan tersebut berkedudukan sebagai fiksional, dalam arti menyusun centang-perenang fakta fisik, interaksi sosial, dan ideologi sehingga bermakna bagi warga untuk menjelaskan kehidupan lingkungannya. Pada titik inilah posisi penjelasan tersebut beragam sesuai dengan pihak bersetara, baik dari pihak akademisi, aparat pemerintahan, swasta, tokoh masyarakat, maupun pihak rakyat jelata. Sejalan dengan itu, di akhir tulisan dikembangkan suatu pengertian "desa" 
yang baru, sebagai hasil solidaritas semua pihak bersama yang mewujud dalam suatu imajinasi desa baru.

\section{Merumuskan Masalah Pertautan Budaya}

Bangunan tulisan ini didirikan di atas asumsi-asumsi kerja berikut. Pertama, warga desa menganut suatu budaya dan struktur sosial yang sesuai dengan sejarah mereka selama ini sehingga sejarah struktur dan kultur tersebut mampu menciptakan suatu identitas diri yang diinginkan. Kedua, pembangunan ${ }^{1}$ desa-yang diwujudkan dalam bentuk proyek pembangunan - merupakan ideologi dan praksis pihak dari luar desa yang mendatangi warga (berikut budaya, struktur sosial, dan sejarah di atas), namun dalam suatu periode waktu, lokasi, dan materi yang terbatas atau singkat. Ketiga, dari asumsi terdahulu muncullah asumsi perbedaan budaya pembangunan dan budaya warga. Keempat, "panggung" atau konteks sosial pembangunan berupa posisi warga yang kian sejajar dengan posisi negara. ${ }^{2}$

Asumsi kerja di atas membalik kebutuhan rumusan pertanyaan selama ini, misalnya upaya romantik untuk menggali kebudayaan lokal yang bersesuaian dengan budaya pembangunan atau modernisasi. Salah satu alasan berasal dari pendukungnya, yaitu secara statistik tidak ada perbedaan signifikan antara peran budaya lokal dan pembangunan karena hampir semua desa sudah mengembangkan gotong royong untuk proyek pembangunan (Gambar 1). Ditolak pula upaya intervensi pembangunan dalam "jaket" kebahasaan lokal, misalnya konsep MAD (Musyawarah Antar Desa) ataupun PEL (Pengembangan Ekonomi Lokal) karena ciri utama pembangunan, sebagai perancangan evolusi kemajuan terencana, tetap melekat. 
Gambar 1.

Jumlah Desa di Indonesia yang Terbiasa Melaksanakan Gotong Royong, 2006

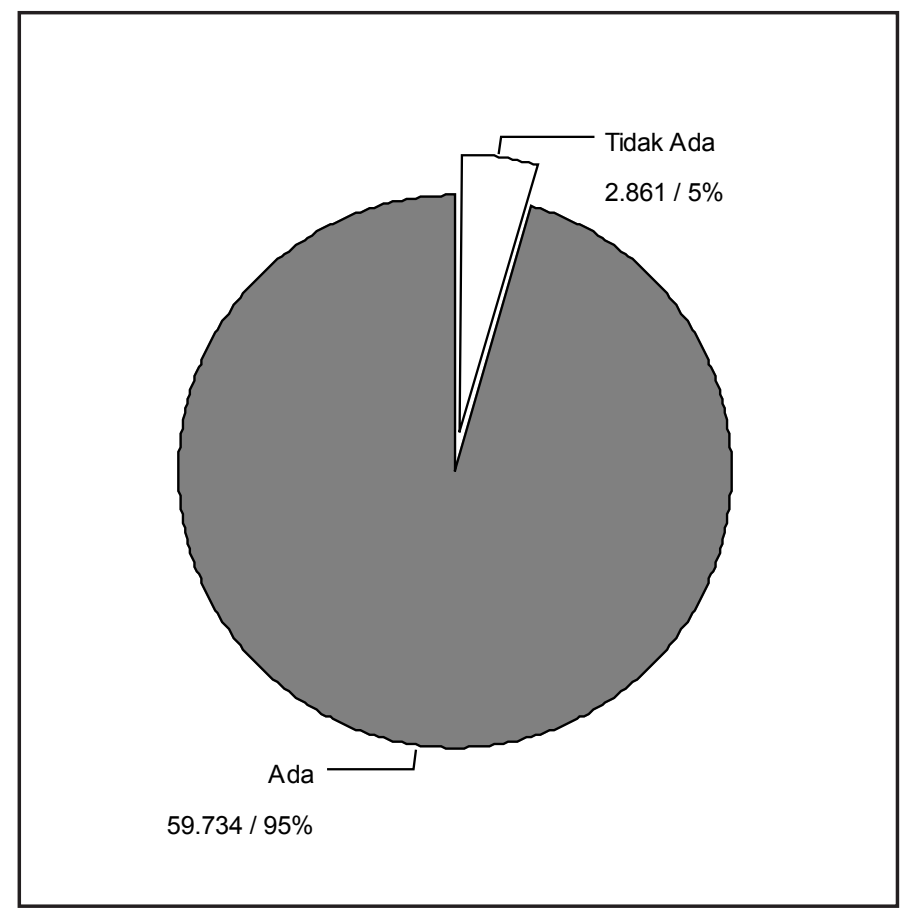

Sumber: Potensi Desa 2006

Imajinasi desa di masa mendatang sebagai bagian dari imajinasi Indonesia membutuhkan "kacamata" baru untuk melihat permasalahan pembangunan desa sebagai problem untuk mempertautkan budaya pembangunan dengan budaya warga. Ragam penjelas lingkungan sosial muncul bersamaan di antara warga dan negara. Realitas bergerak di antara ragam fiksional tersebut dan menghasilkan makna yang berbeda pula ketika memasuki penjelasan yang berbeda. Bagaimana proses yang lebih mendalam pada titik kritis perpindahan makna suatu diskursus dan praksis ketika memasuki fiksional yang berbeda? Bagaimana suatu komunikasi yang diskursif terbangun dalam kehidupan sehari-hari guna menyusun imajinasi suatu imajinasi desa baru? Sampai mana ikatan sosial imajiner dikembangkan menjadi solidaritas bersama, menjadi bahan saling percaya, dan mengembangkan habitus kekuasaan?

\section{Genre "Sampai Mana"}

Setelah sebelumnya disajikan rumusan permasalahan yang relevan bagi budaya desa, selanjutnya bagian ini mengetengahkan pendekatan yang layak digunakan. Pendekatan tersebut ialah genre "Sampai Mana", yang disusun sebagai langkah lebih lanjut dari genre Sajogyo. Orientasi praksis dijadikan landasan bagi pertautan analisis budaya dan struktur sosial. 


\section{LangKah GenRe Sajogyo Selanjutnya}

Berpanggung di atas etika pembangunan-yang dibedakannya dari panggung modernisasi-produksi teks Sajogyo (2006) hakikatnya adalah rajutan jawaban atas fokus pertanyaan "sampai mana". Frasa pertanyaan "sampai mana" mengedepankan jenis ilmu pengetahuan yang bersifat praksis. Artinya, proposisi yang dibangun tertuju kepada tujuan penggunaan teks hasil penelitian itu.

Sayang, aspek tujuan mewujud pada teks evolutif atau historis. Pengaruh ini tidak terelakkan dalam genre Sajogyo. Namun, Sajogyo telah melangkah lebih panjang dengan menggali posisi responden sejauh rentang garis historisnya. Teks dimanfaatkannya pula sebagai wahana evaluasi perubahan responden hingga saat penelitian berlangsung.

Tidak mengherankan produksi teks Sajogyo bersifat post-factum (after the fact) dalam rangka mengevaluasi posisi historis, tetapi sekaligus menyajikan rekomendasi (preskriptif). Aksiologi kegunaan (untuk apa hasil penelitian ini) tidak diterakan dalam teks prediksi masa depan yang netral, melainkan langsung untuk mengelola tujuan. Sajogyo meletakkan sifat teleologis teks guna memihak kepada lapisan bawah. Retorika yang ia bangun bukan sekadar "tujuan apa?", melainkan "dengan cara apa (bagaimana) tujuan dicapai, oleh siapa, dan untuk siapa hasil akhir itu?".

Sikap yang diambil ialah mengembangkan keswadayaan sebagai pengikat kemandirian, kemerdekaan, pemberdayaan, dan penguatan lapisan bawah. Serentak dengan itu, dikembangkan demokratisasi, dalam rupa kerja sama antarpihak serta solidaritas golongan atas kepada golongan lemah. Kedua sisi harus disebut bersamaan agar teks merekam evaluasi tujuan akhir suatu pembangunan bagi warga terlemah.

Yang menarik, dengan landasan dua fondasi, yaitu post factum (deskriptif dan historis) serta preskriptif (rekomendasi hasil penelitian), genre "sampai mana" sejak awal sudah terhindar dari persoalan metodologis kontemporer ilmuwan sosial Indonesia: pengetahuan siapakah yang tercantum dalam teks?

Dalam genre "sampai mana", posisi peneliti, pembawa program, pendamping, guru, dan lain-lainnya berkedudukan setara terhadap masyarakat, yaitu sebagai orang luar yang berminat untuk berinteraksi dengan masyarakat (orang dalam). Genre "sampai mana" mengarahkan metodologi kepada aksi kerja sama, tepatnya bertindak dan belajar bersama warga.

Langkah berikutnya akan memunculkan bagian dalam genre "sampai mana" yang tetap digunakan ialah analisis post-factum (after the fact), aksiologi memihak lapisan bawah, dan mewujudkan demokratisasi. Namun, genre "sampai mana" di sini tidak lagi digunakan sebagai "senjata" pihak luar (akademisi, teknokrat, aparat pemerintah, swasta supra lokal, dan sebagainya) untuk menyusun rekomendasi dan menyusun resep (preskripsi, rekomendasi) pembangunan desa secara sepihak, tetapi digunakan metodologi pragmatis, yaitu kebenaran perencanaan dan preskripsi yang bersumber pada kesepakatan warga desa dan pembawa misi pembangunan. 


\section{PAuTAN Budaya dan STRUKTUR SOSIAL}

Selama bertahun-tahun nilai dan kepercayaan pada kebudayaan menjadi tali yang kuat bagi logika substantif guna mengatur atau menyusun praktik konstitutif sehari-hari. Dengan demikian, sekalipun kondisi peluang bagi beberapa praktik transformasi lingkungannya bersifat historis, praktik konstitutif sehari-hari tersebut juga memberikan dampak penyusunan struktur kumulatif sehingga membatasi pemikiran dan tindakan pada suatu waktu tertentu. Di sinilah bertemu dinamika pembentukan struktur sosial dari budaya yang dinamis.

Yang diusulkan ialah budaya yang muncul sebagai wujud solidaritas dan imajinasi bersama atau wujud hibriditas (Escobar 1999; Robbins 2004). Budaya tersebut muncul sebagai pemberdayaan dari pelaku pembangunan sendiri sehingga solidaritas dari pihak luar hanya dimungkinkan secara sukarela.

\section{KritiK terhadap Budaya Pembangunan Desa}

Bagian ini akan mengembangkan kritik kebudayaan terhadap pembangunan desa sebagaimana dilaksanakan sejak pemerintahan Soeharto. Kritik diarahkan kepada landasan budaya humanisme Kantian, evolusionisme dan perencanaan pembangunan, politik keruangan, serta kapitalisasi pembangunan desa.

\section{KrITIK TERHADAP HUMANISME UNTUK WARGA}

Humanisme Kantian muncul dalam bentuk pemberdayaan bagi Yang Lain (Other), terutama dalam konsep pengembangan kapasitas (capacity building). Menurut Kant, seorang yang dewasa - yang ternyata maksudnya Barat, menurut Said (2001) dan Derrida (Al-Fayyadl 2004)-menjadi seorang humanis, dan dalam dirinya terkandung tugas (deontologis) untuk memberdayakan (meng-humanis-kan) orang lain yang belum dewasa (warga desa di negara Selatan). Pengembangan kapasitas dalam terang humanisme, dengan demikian, merupakan salah satu tutelage (memandang diri memiliki legitimasi untuk menyuluh atau memerintah karena lebih humanistik) untuk menguatkan diskursus pembangunan yang berkelanjutan versi negara Utara.

Humanisme mendasari pandangan bahwa negara Utara lebih maju sehingga lebih humanis. Merekalah yang dipandang dan mendapat legitimasi untuk memajukan negara Selatan. Pembangunan berlangsung secara internasional. Meskipun semula negara maju dan donor internasional yang memberikan utangan, kini mereka menyalahkan negara Selatan, terutama petani dan warga desa, sebagai penyebab degradasi mutu lingkungan sambil tetap memberikan utang bagi perbaikan lingkungan (Escobar 1996). Bersamaan dengan itu, kesenjangan antara negara Utara dan Selatan melebar, baik dalam aspek ekonomi, pendidikan, maupun kerukunan masyarakat lokal (Fernando 2003). 
Di pihak lain, ciri evolutif membuka peluang suatu perencanaan pembangunan (Escobar 1992b, 1996). Perencanaan merupakan penyusunan diskursus di masa depan, dan tidak dapat dinyatakan sebagai realisme. Hanya saja diskursus tersebut terutama dibangun oleh ahli atau elite. Diskursus perencanaan kemudian mendisplinkan pihak lain (Other) yang justru tidak terlibat dalam perencanaan. Ciri tutelage dari penyusun diskursus perencanaan muncul, misalnya di Indonesia, dalam posisi sebagai nara sumber yang memberikan pengarahan isi perencanaan dalam jangka waktu singkat - sehingga tidak memungkinkan dialog (Anwar dan Hadi 1996).

\section{KRITIK TERHADAP EVOlUSIONISME DARI DESA}

Logosentrisme, sebagaimana dikemukakan oleh Descartes ("Aku berpikir maka aku ada"), menghasilkan konsekuensi analisis kausalitas. Bersama dengan pemikiran teleologi, kausalitas ini dapat disusun secara terus-menerus untuk menunjukkan kematangan kemanusiaan (humanisme) atau masyarakat (sejarahnya) (Al-Fayyadl 2005; Venn 2006).

Konsep pembangunan (development) sudah dikenal lama untuk menjelaskan perubahan sosial masyarakat Utara maupun Selatan. Akan tetapi, usai Perang Dunia Kedua, konsep pembangunan memiliki arti tersendiri (Edelman dan Haugerud 2005; Esteva 1992). Bersamaan dengan diskursus pembangunan, diciptakanlah konsep Dunia Ketiga, negara terbelakang, negara sedang berkembang, atau negara Selatan. Dengan kata lain, negara Selatan tidak eksis dengan sendirinya, melainkan tercipta dalam diskursus pembangunan yang disusun negara Utara.

Logosentrisme menerangi pandangan keterbelakangan negara Selatan yang secara evolutif selayaknya mengejar negara maju. Pada awalnya digunakan statistik yang digunakan secara bersama-sama antara Utara dan Selatan. Logos di balik statistik ialah kuantitas atau banyak dipandang baik (Foucault 2002a, 2002b)-yang segera mengingatkan pada prinsip utilitarian. Statistik langsung menunjukkan kekurangan Selatan sekaligus kelebihan Utara dalam pembangunan yang berkelanjutan (Fernando 2003). Hal ini menjadi legitimasi bagi tutelage Utara terhadap Selatan agar mengikutinya.

Sistematika pemikiran di atas berkonsekuensi pada diskursus komunitas sebagai bagian evolusi menuju masyarakat (society). Konsep komunitas disetarakan dengan gemeinschaft menurut Tonnies, atau masyarakat berbasis solidaritas mekanis menurut Durkheim (1933). Komunitas memiliki struktur sosial yang lebih sederhana, diferensiasi sosial lemah, pembagian kerja rendah. Komunitas desa memiliki sifat demikian dan memiliki kebergantungan pada masyarakat perkotaan, sebagaimana dikemukakan dalam teori rural-urban continuиm menurut Redfield. Linearitas semacam inilah yang menjadi bahan dekonstruksi dalam poskolonialisme. Kedudukan kota dipandang lebih tinggi karena di sanalah kosmopolitanisme dikesankan ditumbuhkan, terutama melalui pengumpulan para ahli, institusi kapitalisme, penumpukan tentara (Derrida 2005). Desa menduduki posisi subaltern, yang lebih rendah, tidak bisa menyatakan dirinya sendiri sehingga harus diwakili oleh kota. 
Di samping itu, komunitas mengandung romantisme kerukunan hubungan sosial. Pada marxisme juga - selain tentu saja pemikiran di atas - komunitas primitif (tepatnya: komunisme primitif) tidak mengandung kontradiksi karena tidak memiliki stratifikasi sosial yang berarti. Masyarakat komunis menjadi romantisme utopian tentang kerukunan masyarakat tanpa kelas.

Konsekuensi evolusionisme dalam komunitas tersebut menempatkan komunitas pada posisi yang lebih rendah dan didominasi oleh penjajah. Teks tentang eksploitasi komunitas ditemukan dalam Max Havelaar, karya Multatuli.

Pada masa kini komunitas juga ditempatkan dalam kerangka rasionalisme ekonomi, yakni sebagai salah satu modal sosial (Coleman 1994). Keterpautan tindakan sosial dan ekonomi dalam jaringan komunitas dipandang sebagai akumulasi modal sosial yang berguna untuk menurunkan biaya traksaksi ekonomi.

Instrumentalisasi jaringan komunitas tersebut menafikan kemampuan refleksi diri dari anggota di dalamnya. Di samping itu, sering dijumpai resistensi anggota komunitas terhadap dominasi negara nasional ataupun kolonial.

Argumen evolusionisme ini sulit ditunjukkan di Indonesia, misalnya dengan adanya data kerumitan masyarakat Majapahit dalam aspek perdagangan, pelabuhan, dan ekonomi lain (Hefner 2000). Komunitas Majapahit, sebagai contoh, tersebut memiliki struktur masyarakat yang lebih rumit dari pada masyarakat Eropa pada waktu yang bersamaan.

\section{Kritik terhadap Politik Ruang Desa}

Setidaknya sejak masa Kerajaan Mataram (sekitar abad ke-16) - tepat sebelum dijajah oleh Belanda - desa berkembang dari kemampuan seorang pemimpin untuk mengelola sekelompok warga (Onghokham 1986; Soemardjan 1991). Pengakuan oleh kerajaan diberikan kepada kepala desa tanpa dukungan keuangan atau sumber daya kerajaan lainnya. Kepala desa memproduksi barang dan jasanya sendiri, terutama dengan mengelola warga setempat. Hubungan kepala desa dan kerajaan hanya berlangsung minimal sekali dalam setahun kala memberikan upeti ke kerajaan. Di waktu-waktu peperangan antarkerajaan kepala desa dapat mengerahkan warganya untuk mempertahankan kerajaan. Namun, kepala desa leluasa untuk mengalihkan kepatuhannya kepada kerajaan lain ketika ia memandang rajanya melalaikan keacuhan kepadanya. Dengan kata lain, suatu pembentukan desa selalu menunjukkan kemandirian kepala desa untuk mengelola warganya.

Ketidakmandirian desa dan penempatannya lebih bawah terjadi ketika beberapa desa digabung. Hal ini mulai terjadi dalam masa kolonialisme Hindia Belanda pada awal abad ke-20 (Sajogyo 2006). Ide penggabungan desa tetap dipertahankan sebagai mekanisme kontrol. Di samping dalam bentuk material berupa penggabungan teritorial desa-desa, penggabungan juga muncul dalam diskursus manajerial. Dalam diskursus ini kategorisasi desa dipandang setara sehingga memunculkan kategori desa gabungan 
yang berjumlah secara statistik (tepatnya: sensus) lebih sedikit, merupakan mekanisme untuk mempermudah pengelolaan sekaligus kontrol (Boyne 2006; Venn 2006). Kategorisasi untuk mengontrolnya berupa kecamatan dan kabupaten (terutama sesuai dengan otonomi daerah).

Kontrol terhadap kategori desa - terutama sejak pemerintahan Soehartodimaterialkan dalam pengiriman sumber daya pembangunan dari tingkat nasional, provinsi, kabupaten, kecamatan, lalu ke desa (Nordholt 1987). Materialisasi pembagian inilah yang menguatkan boundary desa melalui pembagian sumber daya sesuai dengan batas (boundary) desa.

Pengategorian sekaligus mencakup kontrol atas desa, terutama dimaterialkan dalam bentuk pemimpin formal yang berperan sebagai penyalur sumber daya pembangunan. Pengontrol ditubuhkan dalam bentuk kepala daerah atau kepala desa. Kepala desa sebagai pemimpin formal semakin menguat terhadap pemimpin informal dalam batas desanya (Nordholt 1987). Sejalan dengan itu peningkatan kebergantungan keuangan desa-sebaliknya penurunan kemandirian keuangan desa lama-muncul sejak 1980-an. Diskursus tentang rantai kontrol secara hierarkis ini tentunya akan menuju kontrol atas keluarga.

Di samping jalur kontrol secara hierarkis tersebut, pemerintah pusat atau daerah dapat langsung mengelola keluarga di desa. Hal ini dilaksanakan melalui kader-kader pembangunan (Sajogyo 2006), contohnya kader keluarga berencana, pembangunan infrastruktur, hukum, keuangan kelompok. Sementara kepala desa mengadakan kontrol teritorial, kader pembangunan melakukan kontrol atas sektor pembangunan.

\section{KritiK terhadap Penyeragaman Kapitalisasi Desa}

Sejak awal pembangunan, desa di Indonesia berkelindan dengan kapitalisme. Modernisasi pertanian, berpangkal dari dua pola usahatani, yaitu pola usahatani sawah di Jawa, dan usahatani perkebunan di luar Jawa (Sajogyo 2006). Adapun perkebunan di luar Jawa masih digambarkan dalam pola perladangan berpindah. Selama masa Orde Baru (1969-1997) modernisasi pertanian berada di atas konteks industrialisasi Indonesia.

Kritik terhadap budaya kapitalis diarahkan pada oksidentalisme sebagai hasil dari rasionalitas kapitalis, kolonialisme Barat, dan modernitas instrumental atau positivistik. Etika kapitalisme tersebut berafiliasi dengan pemenuhan kebutuhan bagi diri sendiri, otonomi, subjek rasional sehingga manusia diposisikan sebagai agen sejarah dan pengetahuan. Privilese manusia ini konsisten dengan logika intrinsik kapitalisme, artinya hubungan antarmanusia diekspresikan secara impersonal, dehumanisasi dan bahasa yang abstrak sebagai hubungan antarbenda. Reartikulasi bahaya abstraksi tersebut muncul dalam diskursus efisiensi ekonomis dan teknologis serta kemajuan yang secara tautologis merujuk pada legitimasi tujuan spesifikasi teknis dan performatif menurut diskursus itu sendiri.

Pada saat ini muncul isu bahwa kapitalisme tidaklah tunggal, namun beragam dan bisa muncul dalam masyarakat desa di Timur. Hal ini diarahkan 
oleh tesis keterlekatan (embeddedness), bahwa keragaman itu muncul akibat bekerjanya aspek struktur dan kultur lokal dalam kapitalisme dan globalisme sekalipun.

Namun, tesis keterlekatan tetap mengandung kritik. Pertama, konteks globalisasi telah mengerucutkan aspek historis ekonomi lokal menjadi hanya "mengekor" kepada sejarah kapitalisme. Meskipun memiliki ciri-ciri pluralitas, ekonomi lokal dipandang sedang sama-sama mengarah kepada kapitalisme dan saling bertaut menjadi globalisme. Sampai di sini dikesampingkan aspek kesejarahan Eropa (dan Amerika Utara, serta Jepang, pendeknya negara maju) dalam melakukan hegemoni ideologis ekonomis pada negara Selatan.

Kedua, tesis keterlekatan masa kini mengesampingkan aspek politis kapitalisme, terutama eksoploitasi ruang desa, lapisan, kelompok atau kelas bawah oleh lapisan elite. Kembali di sini dilepaskan penjelasan eksploitasi negara Utara terhadap negara Selatan karena semuanya dipandang samasama berada dalam ranah kapitalisme dan globalisasi. Lebih jauh lagi, sukar ditunjukkan eksploitasi lapisan atas kepada lapisan bawah dalam suatu negara Selatan.

\section{Keragaman Budaya Warga Desa}

Setelah dekonstruksi diarahkan kepada laju pembangunan desa selama ini yang mengarah kepada keseragaman kapitalisme global, pada bagian ini disajikan pembacaan yang berbeda berupa keragaman wajah budaya warga. Keragaman tersebut mewujud dalam ruang kosmopolitan di desa dan keragaman budaya ekonomi.

\section{Ruang Kosmopolitan di Desa}

Penyusunan suatu "desa" baru kiranya semakin sulit didasarkan pada entitas etnis dan modal sosial lama (sebelum penyeragaman desa ala UU $5 / 79$, sebelum penggabungan banyak desa awal abad ke-20, sebelum kolonialisme). Pertama, lebih dari separuh (60 persen) ruang desa di Indonesia sudah terisi lebih dari satu etnis (Tabel 1). Kedua, pada dasarnya setiap etnis bersifat poliglot atau selalu bersifat menjadi (being) dalam rangka memadukan percampuran beragam fiksional (termasuk percampuran lewat perkawinan ataupun ketetanggaan dari beragam suku bangsa).

Keadaan di atas justru menunjukkan peluang pengembangan kosmopolitanisme di desa. Hubungan keindonesiaan dapat dibangun sebagai imajinasi baru bagi penataan ruang yang sesuai dengan kebutuhan lokal antaretnis.

Sejalan dengan keragaman etnis tersebut, muncul pula pertautannya dengan pola-pola saling percaya antarwarga dan terhadap pihak luar. Rasa saling percaya dibangun di atas habituasi, yaitu dilanggengkan dalam pola kehidupan sehari-hari. 
Tabel 1.

Jumlah Desa menurut Keragaman Etnis di Indonesia

\begin{tabular}{|c|c|c|c|}
\hline Propinsi & Etnis Tunggal & $\begin{array}{c}\text { Etnis Lebih } \\
\text { dari Satu }\end{array}$ & Jumlah \\
\hline \multirow{2}{*}{$\begin{array}{l}\text { Nanggroe } \\
\text { Aceh Darussalam }\end{array}$} & 3570 & 2271 & 5841 \\
\hline & $61,1 \%$ & $38,9 \%$ & $100,0 \%$ \\
\hline Sumatera Utara & $\begin{array}{l}1377 \\
31,6 \%\end{array}$ & $\begin{array}{l}2975 \\
68,4 \%\end{array}$ & $\begin{array}{l}4352 \\
100,0 \%\end{array}$ \\
\hline Sumatera Barat & $\begin{array}{l}260 \\
40,3 \%\end{array}$ & $\begin{array}{l}385 \\
59,7 \%\end{array}$ & $\begin{array}{l}645 \\
100.0 \%\end{array}$ \\
\hline Riau & \begin{tabular}{|l|}
179 \\
$13,9 \%$
\end{tabular} & $\begin{array}{l}1106 \\
86,1 \%\end{array}$ & \begin{tabular}{|l|}
1285 \\
$100,0 \%$
\end{tabular} \\
\hline Jambi & \begin{tabular}{|l|}
268 \\
$24,3 \%$ \\
\end{tabular} & \begin{tabular}{|l|l|}
836 \\
$75,7 \%$ \\
\end{tabular} & \begin{tabular}{|l|}
1104 \\
$100,0 \%$
\end{tabular} \\
\hline Sumatera Selatan & \begin{tabular}{|l|l|}
608 \\
$24,6 \%$
\end{tabular} & $\begin{array}{l}1864 \\
75,4 \% \\
\end{array}$ & \begin{tabular}{|l|}
2472 \\
$100,0 \%$
\end{tabular} \\
\hline Bengkulu & \begin{tabular}{|l|}
313 \\
$28,0 \%$
\end{tabular} & \begin{tabular}{|l|}
806 \\
$72,0 \%$ \\
\end{tabular} & \begin{tabular}{|l|}
1119 \\
$100,0 \%$
\end{tabular} \\
\hline Lampung & $\begin{array}{l}186 \\
9,2 \%\end{array}$ & $\begin{array}{l}1833 \\
90,8 \%\end{array}$ & $\begin{array}{l}2019 \\
100,0 \%\end{array}$ \\
\hline Bangka Belitung & $\begin{array}{l}18 \\
6,7 \% \\
\end{array}$ & \begin{tabular}{|l|}
250 \\
$93,3 \%$ \\
\end{tabular} & \begin{tabular}{|l|}
268 \\
$100,0 \%$
\end{tabular} \\
\hline Kepulauan Riau & \begin{tabular}{|l|}
16 \\
$10,8 \%$ \\
\end{tabular} & $\begin{array}{l}132 \\
89,2 \%\end{array}$ & $\begin{array}{l}148 \\
100,0 \%\end{array}$ \\
\hline Jawa Barat & $\begin{array}{l}1583 \\
30,5 \%\end{array}$ & $\begin{array}{l}3611 \\
69,5 \% \\
\end{array}$ & \begin{tabular}{|l|}
5194 \\
$100,0 \%$
\end{tabular} \\
\hline Jawa Tengah & \begin{tabular}{|l|}
4963 \\
$63,6 \%$
\end{tabular} & $\begin{array}{l}2842 \\
36,4 \%\end{array}$ & \begin{tabular}{|l|}
7805 \\
$100,0 \%$
\end{tabular} \\
\hline DI Yogyakarta & \begin{tabular}{|l|}
197 \\
$50,1 \%$
\end{tabular} & $\begin{array}{l}196 \\
49,9 \%\end{array}$ & \begin{tabular}{|l|}
393 \\
$100,0 \%$
\end{tabular} \\
\hline Jawa Timur & \begin{tabular}{|l|}
4506 \\
$58,5 \%$
\end{tabular} & $\begin{array}{l}3194 \\
41,5 \%\end{array}$ & \begin{tabular}{|l|}
7700 \\
$100,0 \%$
\end{tabular} \\
\hline Banten & \begin{tabular}{|l|}
386 \\
$29,2 \%$
\end{tabular} & $\begin{array}{l}937 \\
70,8 \%\end{array}$ & \begin{tabular}{|l|}
1323 \\
$100,0 \%$ \\
\end{tabular} \\
\hline Bali & \begin{tabular}{|l|}
251 \\
$40,4 \%$
\end{tabular} & $\begin{array}{l}371 \\
59,6 \%\end{array}$ & \begin{tabular}{|l|}
622 \\
$100,0 \%$
\end{tabular} \\
\hline Nusa Tenggara Barat & \begin{tabular}{|l|}
168 \\
$23,1 \%$
\end{tabular} & \begin{tabular}{|l|}
560 \\
$76,9 \%$
\end{tabular} & $\begin{array}{l}728 \\
100,0 \%\end{array}$ \\
\hline Nusa Tenggara Timur & \begin{tabular}{|l|}
1119 \\
$45,7 \%$
\end{tabular} & $\begin{array}{l}1330 \\
54,3 \%\end{array}$ & \begin{tabular}{|l|}
2449 \\
$100,0 \%$
\end{tabular} \\
\hline Kalimantan Barat & \begin{tabular}{|l|}
210 \\
$14,5 \%$
\end{tabular} & $\begin{array}{l}1241 \\
85,5 \%\end{array}$ & \begin{tabular}{|l|}
1451 \\
$100,0 \%$
\end{tabular} \\
\hline
\end{tabular}




\begin{tabular}{|l|l|l|l|}
\hline \multicolumn{1}{|c|}{ Propinsi } & \multicolumn{1}{|c|}{ Etnis Tunggal } & \multicolumn{1}{c|}{$\begin{array}{c}\text { Etnis Lebih } \\
\text { dari Satu }\end{array}$} & Jumlah \\
\hline Kalimantan Tengah & 234 & 1006 & 1240 \\
& $18,9 \%$ & $81,1 \%$ & $100,0 \%$ \\
\hline Kalimantan Selatan & 582 & 1254 & 1836 \\
& $31,7 \%$ & $68,3 \%$ & $100,0 \%$ \\
\hline Kalimantan Timur & 265 & 887 & 1152 \\
& $23,0 \%$ & $77,0 \%$ & $100,0 \%$ \\
\hline Sulawesi Utara & 236 & 750 & 986 \\
& $23,9 \%$ & $76,1 \%$ & $100,0 \%$ \\
\hline Sulawesi Tengah & 146 & 1252 & 1398 \\
& $10,4 \%$ & $89,6 \%$ & $100,0 \%$ \\
\hline Sulawesi Selatan & 1021 & 1508 & 2529 \\
& $40,4 \%$ & $59,6 \%$ & $100,0 \%$ \\
\hline Sulawesi Tenggara & 266 & 1142 & 1408 \\
& $18,9 \%$ & $81,1 \%$ & $100,0 \%$ \\
\hline Gorontalo & 102 & 281 & 383 \\
& $26,6 \%$ & $73,4 \%$ & $100,0 \%$ \\
\hline Maluku & 331 & 504 & 835 \\
& $39,6 \%$ & $60,4 \%$ & $100,0 \%$ \\
\hline Maluku Utara & 153 & 545 & 698 \\
& $21,9 \%$ & $78,1 \%$ & $100,0 \%$ \\
\hline Papua & 1836 & 1376 & 3212 \\
& $57,2 \%$ & $42,8 \%$ & $100,0 \%$ \\
\hline INDONESIA & 25350 & 37245 & 62595 \\
& $40,5 \%$ & $59,5 \%$ & $100,0 \%$ \\
\hline
\end{tabular}

Sumber: Potensi Desa 2006

\section{Keragaman Budaya EKONOMI}

Dalam pandangan modernisme, budaya ekonomis dipandang secara tunggal. Memang terdapat pandangan tentang subkultur budaya ekonomi, namun tetap diterima tesis keberadaan inti budaya. Inti budaya sering dipahami sebagai unsur kebudayaan yang tidak dapat atau hampir mustahil diubah. Oleh sebab itu, inti budaya dapat kita maknai sebagai pengikat budaya, dan inilah yang mendasari pemahaman ketunggalan kebudayaan. Sebagai contoh, budaya Jawa meliputi subkultur santri, abangan, priyayi, mungkin juga jenis lainnya di wilayah Jawa Tengah bagian selatan di sebelah barat Yogyakarta. Meskipun terlihat beragam pada level subkultur, inti budaya Jawa tetap sama, yaitu selametan (perjamuan sekaligus doa bersamasama) untuk menandai peristiwa kehidupan yang penting.

Didasari pandangan tentang inti budaya, tesis keterlekatan dalam modernisme ekonomi diterapkan untuk menyusun argumen adanya aspek kapitalisme pada kebudayaan non-Barat di Asia, termasuk Indonesia di atas 
(Hefner 2000). Namun, kritik dapat dikembangkan, yaitu temuannya akan menunjukkan bahwa kapitalisme merupakan unsur kebudayaan universal. Hal ini berarti memunculkan monolingualisme atau tirani nilai kapitalisme untuk mematikan praktik dan narasi alternatif. Sistematisasi nilai ini dirangkum dalam rasionalisasi kemodernan. Lebih tajam lagi, kemajemukan kapitalisme juga menunjukkan aspek poliglot, namun ketika muncul di negara bekas jajahan berarti subalternisasi (peletakan kebudayaan Timur lebih rendah atau tersubordinasi oleh kebudayaan Barat).

Berlawanan dengan pandangan ketunggalan budaya ekonomis tersebut, teori poskolonial memandang budaya bersifat poliglot. Tidak ada inti budaya sehingga dihilangkan konsep budaya asli (Said 1995, 2001). Setiap budaya merupakan percampuran dari beragam aspek lingkungannya. Ciri poliglot memandang kapitalisme di suatu tempat sebagai hasil percampuran budaya terdahulu dengan kapitalisme. Pola ekonomi suatu masyarakat dipandang sebagai keseluruhan percampuran budaya di sana, bukan pencerminan universalisme kapitalisme (bahkan meskipun muncul pasar pencipta harga di sana).

Dalam pandangan subaltern, kapitalisme Timur berposisi lebih rendah sehingga, dengan kemajuan budaya dan sosial lokal akan menuju atau menyamai kapitalisme Barat. Kapitalisme Timur tidak dipandang terpisah dan mandiri, melainkan selalu dikaitkan dengan kapitalisme Barat yang lebih maju sehingga perbedaan laju kapitalisme di Timur senantiasa ditanggapi secara peyoratif. Contohnya pengembangan konsep kapitalisme semu (ersatz capitalism) untuk masyarakat di Asia Tenggara.

Sejalan dengan keragaman etnis di dalam desa di Indonesia, analisis ekonomi pertanian dan ekonomi desa juga tidak bisa diletakkan di atas asumsi ketunggalan struktur ekonomi. Lihat Tabel 2. Jika menggunakan pembedaan penerimaan pasar sebagai tanda penerimaan kapitalisme, ternyata adopsi kapitalisme terhadap komoditas pertanian hanya dominan pada 19 persen (11.756) desa di Indonesia. Selain itu, bahkan sebanyak 8 persen (4.800) desa didominasi oleh perekonomian nonmoneter. Pada mayoritas desa di Indonesia (46.039 desa atau 76 persen) ternyata berkembang koartikulasi antara ekonomi kapitalis (moneter) dan nonmoneter. 
Tabel 2.

Jumlah Desa tiap Propinsi di Indonesia menurut Monetisasi Produk Pertanian

\begin{tabular}{|c|c|c|c|c|}
\hline Propinsi & Dijual & $\begin{array}{c}\text { Dikonsumsi } \\
\text { dan Dijual }\end{array}$ & $\begin{array}{c}\text { Dikonsumsi } \\
\text { Sendiri }\end{array}$ & Jumlah \\
\hline \multirow{2}{*}{$\begin{array}{l}\text { Nanggroe Aceh } \\
\text { Darussalam }\end{array}$} & 562 & 4688 & 591 & 5841 \\
\hline & $9,6 \%$ & $80,3 \%$ & $10,1 \%$ & $100,0 \%$ \\
\hline Sumatera Utara & $\begin{array}{l}1381 \\
31,7 \% \\
\end{array}$ & $\begin{array}{l}2659 \\
61,1 \% \\
\end{array}$ & $\begin{array}{l}312 \\
7,2 \% \\
\end{array}$ & $\begin{array}{l}4352 \\
100,0 \% \\
\end{array}$ \\
\hline Sumatera Barat & $\begin{array}{l}111 \\
17,2 \%\end{array}$ & $\begin{array}{l}459 \\
71,2 \%\end{array}$ & $\begin{array}{l}75 \\
11,6 \%\end{array}$ & \begin{tabular}{|l|}
645 \\
$100,0 \%$
\end{tabular} \\
\hline Riau & $\begin{array}{l}867 \\
67,5 \% \\
\end{array}$ & $\begin{array}{l}394 \\
30,7 \% \\
\end{array}$ & $\begin{array}{l}24 \\
1,9 \% \\
\end{array}$ & \begin{tabular}{|l|}
1285 \\
$100,0 \%$ \\
\end{tabular} \\
\hline Jambi & $\begin{array}{l}639 \\
57,9 \% \\
\end{array}$ & $\begin{array}{l}369 \\
33,4 \% \\
\end{array}$ & \begin{tabular}{|l|}
96 \\
$8,7 \%$ \\
\end{tabular} & \begin{tabular}{|l|}
1104 \\
$100,0 \%$ \\
\end{tabular} \\
\hline Sumatera Selatan & $\begin{array}{l}944 \\
38,2 \% \\
\end{array}$ & $\begin{array}{l}1422 \\
57,5 \%\end{array}$ & $\begin{array}{l}106 \\
4,3 \% \\
\end{array}$ & \begin{tabular}{|l|}
2472 \\
$100,0 \%$ \\
\end{tabular} \\
\hline Bengkulu & $\begin{array}{l}486 \\
43,4 \%\end{array}$ & $\begin{array}{l}563 \\
50,3 \% \\
\end{array}$ & \begin{tabular}{|l|}
70 \\
$6,3 \%$ \\
\end{tabular} & \begin{tabular}{|l|}
1119 \\
$100,0 \%$ \\
\end{tabular} \\
\hline Lampung & $\begin{array}{l}654 \\
32,4 \% \\
\end{array}$ & $\begin{array}{l}1299 \\
64,3 \% \\
\end{array}$ & \begin{tabular}{|l|l|}
66 \\
$3,3 \%$ \\
\end{tabular} & \begin{tabular}{|l|}
2019 \\
$100,0 \%$ \\
\end{tabular} \\
\hline Bangka Belitung & $\begin{array}{l}90 \\
33,6 \% \\
\end{array}$ & $\begin{array}{l}178 \\
66,4 \% \\
\end{array}$ & $\begin{array}{l}0 \\
, 0 \% \\
\end{array}$ & $\begin{array}{l}268 \\
100,0 \% \\
\end{array}$ \\
\hline Kepulauan Riau & $\begin{array}{l}29 \\
19,6 \% \\
\end{array}$ & $\begin{array}{l}119 \\
80,4 \%\end{array}$ & $\begin{array}{l}0 \\
, 0 \% \\
\end{array}$ & \begin{tabular}{|l|}
148 \\
$100,0 \%$ \\
\end{tabular} \\
\hline Jawa Barat & $\begin{array}{l}267 \\
5,1 \% \\
\end{array}$ & $\begin{array}{l}4607 \\
88,7 \% \\
\end{array}$ & $\begin{array}{l}320 \\
6,2 \% \\
\end{array}$ & \begin{tabular}{|l|}
5194 \\
$100,0 \%$ \\
\end{tabular} \\
\hline Jawa Tengah & \begin{tabular}{|l|}
717 \\
$9,2 \%$ \\
\end{tabular} & $\begin{array}{l}6794 \\
87,0 \% \\
\end{array}$ & \begin{tabular}{|l|}
294 \\
$3,8 \%$ \\
\end{tabular} & \begin{tabular}{|l|}
7805 \\
$100,0 \%$ \\
\end{tabular} \\
\hline DI Yogyakarta & $\begin{array}{l}6 \\
1,5 \% \\
\end{array}$ & $\begin{array}{l}367 \\
93,4 \% \\
\end{array}$ & \begin{tabular}{|l|}
20 \\
$5,1 \%$ \\
\end{tabular} & \begin{tabular}{|l|}
393 \\
$100,0 \%$ \\
\end{tabular} \\
\hline Jawa Timur & $\begin{array}{l}807 \\
10,5 \% \\
\end{array}$ & $\begin{array}{l}6665 \\
86,6 \% \\
\end{array}$ & \begin{tabular}{|l|}
228 \\
$3,0 \%$ \\
\end{tabular} & \begin{tabular}{|l|}
7700 \\
$100,0 \%$ \\
\end{tabular} \\
\hline Banten & $\begin{array}{l}57 \\
4,3 \% \\
\end{array}$ & $\begin{array}{l}1091 \\
82,5 \%\end{array}$ & \begin{tabular}{|l|}
175 \\
$13,2 \%$ \\
\end{tabular} & $\begin{array}{l}1323 \\
100,0 \% \\
\end{array}$ \\
\hline Bali & $\begin{array}{l}108 \\
17,4 \%\end{array}$ & $\begin{array}{l}475 \\
76,4 \%\end{array}$ & $\begin{array}{l}39 \\
6,3 \% \\
\end{array}$ & $\begin{array}{l}622 \\
100,0 \%\end{array}$ \\
\hline Nusa Tenggara Barat & $\begin{array}{l}48 \\
6,6 \% \\
\end{array}$ & $\begin{array}{l}660 \\
90,7 \% \\
\end{array}$ & $\begin{array}{l}20 \\
2,7 \% \\
\end{array}$ & \begin{tabular}{|l|}
728 \\
$100,0 \%$ \\
\end{tabular} \\
\hline Nusa Tenggara Timur & $\begin{array}{l}269 \\
11,0 \% \\
\end{array}$ & $\begin{array}{l}1649 \\
67,3 \% \\
\end{array}$ & \begin{tabular}{|l}
531 \\
$21,7 \%$ \\
\end{tabular} & \begin{tabular}{|l|}
2449 \\
$100,0 \%$ \\
\end{tabular} \\
\hline Kalimantan Barat & $\begin{array}{l}571 \\
39,4 \% \\
\end{array}$ & $\begin{array}{l}674 \\
46,5 \% \\
\end{array}$ & $\begin{array}{l}206 \\
14,2 \% \\
\end{array}$ & $\begin{array}{l}1451 \\
100,0 \% \\
\end{array}$ \\
\hline
\end{tabular}




\begin{tabular}{|l|l|l|l|l|}
\hline Propinsi & \multicolumn{1}{|c|}{ Dijual } & $\begin{array}{c}\text { Dikonsumsi } \\
\text { dan Dijual }\end{array}$ & $\begin{array}{c}\text { Dikonsumsi } \\
\text { Sendiri }\end{array}$ & Jumlah \\
\hline Kalimantan Tengah & 342 & 696 & 202 & 1240 \\
& $27,6 \%$ & $56,1 \%$ & $16,3 \%$ & $100,0 \%$ \\
\hline Kalimantan Selatan & 284 & 1440 & 112 & 1836 \\
& $15,5 \%$ & $78,4 \%$ & $6,1 \%$ & $100,0 \%$ \\
\hline Kalimantan Timur & 92 & 775 & 285 & 1152 \\
& $8,0 \%$ & $67,3 \%$ & $24,7 \%$ & $100,0 \%$ \\
\hline Sulawesi Utara & 320 & 651 & 15 & 986 \\
& $32,5 \%$ & $66,0 \%$ & $1,5 \%$ & $100,0 \%$ \\
\hline Sulawesi Tengah & 557 & 803 & 38 & 1398 \\
& $39,8 \%$ & $57,4 \%$ & $2,7 \%$ & $100,0 \%$ \\
\hline Sulawesi Selatan & 549 & 1819 & 161 & 2529 \\
& $21,7 \%$ & $71,9 \%$ & $6,4 \%$ & $100,0 \%$ \\
\hline Sulawesi Tenggara & 387 & 988 & 33 & 1408 \\
& $27,5 \%$ & $70,2 \%$ & $2,3 \%$ & $100,0 \%$ \\
\hline Gorontalo & 26 & 351 & 6 & 383 \\
& $6,8 \%$ & $91,6 \%$ & $1,6 \%$ & $100,0 \%$ \\
\hline Maluku & 140 & 633 & 62 & 835 \\
& $16,8 \%$ & $75,8 \%$ & $7,4 \%$ & $100,0 \%$ \\
\hline Maluku Utara & 125 & 560 & 13 & 698 \\
& $17,9 \%$ & $80,2 \%$ & $1,9 \%$ & $100,0 \%$ \\
\hline Papua & 321 & 2191 & 700 & 3212 \\
& $10,0 \%$ & $68,2 \%$ & $21,8 \%$ & $100,0 \%$ \\
\hline INDONESIA & 11756 & 46039 & 4800 & 62595 \\
& $18,8 \%$ & $73,6 \%$ & $7,7 \%$ & $100,0 \%$ \\
\hline
\end{tabular}

Sumber: Potensi Desa 2006 (Diolah)

Tafsir atas data tersebut menunjukkan kebutuhan analisis dan tindakan yang sesuai dengan pluralitas struktur ekonomi-bukan pluralitas kapitalisme. Kemampuan hibriditas menjadi penting untuk menjaga hubungan antarstruktur ekonomi tersebut. Lebih jauh lagi, menyadari proporsi monetisasi desa yang rendah-bahkan proporsi pada provinsi di Jawa dapat lebih rendah daripada provinsi di luar Jawa. Maka, dapat dinyatakan bahwa upaya untuk mendesakkan struktur kapitalisme atau globalisme yang berasal dari Barat pada semua desa di Indonesia merupakan salah satu bentuk subalternisasi atau kontrol Barat terhadap Timur.

\section{Kesimpulan: "FAMILIASI" Basis KeINDONESIAAN}

Setelah disandingkan budaya pembangunan yang berpotensi menyeragamkan dan budaya warga yang beragam, kini saatnya untuk membangun imajinasi baru bagi Indonesia di masa mendatang. Mula-mula akan disajikan kesimpulan mengenai pentingnya dimensi toleransi dalam 
koartikulasi antarpihak yang melakukan transformasi sosial. Kemudian diusulkan pengembangan imajinasi ruang baru untuk menempatkan arti "desa". Dalam proses konstruksi demikian, diusulkan untuk mengembangkan praksis familiasi. Agar terfokus kepada lapisan bawah, konstruksi familiasi diarahkan untuk menguatkan lapisan bawah.

\section{BASIS TOLERANSI}

Menghindar dari revolusi yang bersifat dadakan, melainkan mengembangkan hibriditas dalam kehidupan sehari-hari, maka selayaknya warga desa menciptakan diskursus bagi dirinya sendiri, terutama yang paling cocok dengan keadaan masyarakatnya sendiri. Hubungan yang erat antara diskursus, tindakan sosial, dan infrastruktur (Althusser 2004) menunjukkan peluang sekaligus legitimasi bagi penyusunan diskursus oleh warga sendiri.

Untuk menghindari logosentrisme, proses konstruksi tersebut tidak merupakan definisi yang sudah jadi dari luar desa. Berlawanan dengan hal tersebut, politik konstruksi kebenaran senantiasa dipertimbangkan oleh beragam pihak secara dinamis, terutama dari kelompok marginal di dalam "desa". Sejarah (dan perencanaan sebagai implikasinya) dilaksanakan secara dinamis dan selalu dalam posisi "menjadi", bukan definisi yang sudah jadi (Being dalam konsep Heidegger). Klaim kebenaran tidak mungkin dipaksakan oleh salah satu pihak, tetapi dipertimbangkan secara bersama-sama - bahkan kebenaran tersebut didefinisikan bersama-sama pula karena bukan sesuai dengan yang sudah jadi atau sudah ada.

Upaya warga desa untuk memilih, meminjam, menyerap, menggunakan, mengadaptasi budaya pembangunan berlangsung dalam proses dinamis secara terus-menerus, yang biasa disebut hibriditas. Melalui konsep hibriditas inilah dapat dikemukakan emansipasi warga desa atau suara mereka. Halhal yang dipandang sebagai modal sosial desa, dalam perspektif lainnya, sebenarnya merupakan hibriditas warga dan budaya lokal.

Hibriditas menunjukkan upaya mengambil, meminjam, mengubah diri untuk merespon pihak luar (Venn 2006). Meskipun pada akhirnya berada pada posisi kultural, penerimaan kultur hibrid tersebut melalui tindakan seharihari yang berlangsung lama. Konsep lain yang sama dengannya dinamakan kreolisme.

Hibriditas dapat mengaburkan identitas - minimal identitas awal. Sebagaimana kultur yang selalu bersifat campuran (polyglot), maka identitas pun bersifat demikian. Ciri polyglot ini mengaburkan representasi sosial dan budaya yang kaku. Ciri ini juga memungkinkan hibriditas terjadi di antara pihak-pihak yang bersetuju pada diskursus atau habitus yang sama. Konsep hibriditas dengan demikian memungkinkan solidaritas antaraktor meskipun lintas kelas, hierarki sosial, atau kategori sosial lain -asal bersetuju dalam diskursus.

Jika imajinasi desa di masa mendatang masih dikaitkan dengan proses pembangunan, ada baiknya dimaknai ulang sebagai suatu kondisi keberadaan 
bersama-sama (koartikulasi) di antara beragam diskursus dan praksis dari beragam agensi. Sebagai langkah awal, kategorisasi agensi yang terlibat digolongkan ke dalam pemerintah, swasta, dan masyarakat. Koartikulasi yang dikembangkan berupa toleransi: hubungan antaragensi berupa hibriditas ketika beragam pihak melakukan penerjemahan diskursus dan praksis pembangunan untuk menguatkan identitas diri historis masingmasing sekaligus memungkinkan penghitungan manfaat bagi agensi lain yang terlibat.

\section{IMAJINASI RUANG BARU}

Ikatan - sekaligus batas-batas-komunitas dapat dipandang sebagai konstruksi kesadaran di antara warganya, yang ditunjukkan dalam hubungan sosial sehari-hari serta pembentukan materi yang sesuai. Hubungan dengan pihak luar dikelola dalam bentuk hibriditas, yaitu memahami-tepatnya merefleksikan - hal-hal baru menurut kesadaran dirinya sendiri, atau menurut "bahasanya sendiri" (Anderson 2002; Venn 2006). Kesadaran bersama itu menjadi penegas (judgement) bagi kebenaran suatu makna transformasi ruang di sana.

Konsep hibriditas secara kritis dapat mengarahkan penggunaan secara bersama-sama keseluruhan aspek lingkungan warga bagi semua pihak yang terlibat dalam arti seluas-luasnya. Konstruksi oleh pihak-pihak yang selama ini tertindas dibuka peluangnya sehingga pluralitas makna bagi transformasi ruang tersebut dimungkinkan. Pluralitas makna inilah yang memungkinkan beragam pihak untuk melakukan hibriditas kultural. Konsep hibriditas memungkinkan solidaritas lintas posisi sosial dari level lokal hingga internasional. Lebih jauh lagi, hibriditas memungkinkan globalisasi dari bawah atau dari kelompok marjinal.

\section{Peluang "Familiasi"}

Di sini hendak diajukan proposisi bahwa pengembangan struktur interaksi antaragensi pada masa depan desa Indonesia didasarkan pada penerjemahan ikatan keluarga dan analogi keluarga dalam interaksi yang lebih luas. Struktur imajiner keluarga mendahului penyusunan komunitas imajiner di tingkat desa maupun lingkup proyek pembangunan dan modernisasi yang lebih luas.

Keluarga dimaknai secara baru sebagai struktur sosial yang dipahami dan diciptakan secara terus-menerus oleh warga desa sehingga menciptakan bias dalam mengevaluasi dan menciptakan struktur sosial yang lebih luas Sejarah hubungan keluarga dan desa menunjukkan peluang toleransi antaragensi, mengingat keluarga memiliki suatu ruang untuk membebaskan diri. Tentu saja disadari kolonisasi sistem yang lebih luas terhadap keluarga tersebut. Hal inilah yang mendorong penyusunan struktur sosial baru menurut imajinasi interaksi dalam keluarga. Di sinilah muncul peluang penyusunan komunitas imajiner melalui familiasi (imajinasi struktur keluarga sebagai penerjemah segala hal dari luar). 
Mula-mula perlu disadari kesulitan dalam mendukung argumen sebagian pihak (Malarangeng 2002), bahwa diskursus paradigma ekonomi dominan (mazhab neoklasik, globalisasi atau neoliberalisme) telah memenuhi tata aturan ekonomi di Indonesia. Mungkin benar bahwa pelembagaan diskursus ini berlangsung di lingkaran elite teknokrat, dan terlembaga pula dalam beberapa kebijakan ekonomi. Akan tetapi, kebijakan tersebut dapat saling bersilangan, misalnya upaya deregulasi di pusat yang diikuti regulasi di daerah. Deregulasi perbankan, misalnya, sekaligus diikuti regulasi peningkatan beragam pajak nasabah dan bank. Oleh karena itu, lebih aman berargumen bahwa pelembagaan kapitalisme, neoliberalisme, atau globalisasi belum berlangsung secara memadai (Irwan 2005). Data monetisasi perdesaan di atas juga menunjukkan rendahnya pelembagaan kapitalisme Barat. Ketidakpastian hukum bagi kegiatan ekonomi ini sulit dipandang sebagai tindakan kebetulan karena kenyataannya ketidakpastian hukum justru sering digunakan oleh penguasa untuk menarik rente lebih tinggi dari warga (Heryanto 2000).

Pelembagaan narasi besar tersebut semakin terlihat gagal manakala faktor keluarga ternyata mengemuka (Irwan 2005). Imajinasi ikatan keluarga mendasari korupsi, kolusi, dan nepotisme dalam kapitalisme. Analisis yang bersumber dari aksioma rasionalisme atau humanisme Barat (asumsi bahwa manusia cenderung menggunakan rasionya) tersebut sulit mendalami peran keluarga atau kekeluargaan dalam ekonomi kapitalis sehari-hari. Mula-mula hal ini disebabkan pemisahan ruang publik (ekonomi formal) dan privat (keluarga), yang sejalan dengan upaya menguatkan impersonalisme dalam kapitalisme. Keluarga, korupsi, kolusi, dan nepotisme tidaklah rasional atau menunjukkan humanisme sehingga tidak sahih untuk dianalisis.

Sampai di sini konsep familiasi bisa dibangun. Keluarga dapat masuk dan menguat ke dalam jaringan politik ekonomi Indonesia sejalan dengan kondisi kesejarahan yang berbeda dari Barat maupun Jepang. Konsep keluarga inti, misalnya, dipandang sebagai susunan Barat setelah revolusi industri. Hingga awal abad ke-20 keluarga inti dipandang secara peyoratif, sebagai hasil yang tidak diinginkan dari revolusi industri yang memecah kesatuan kerabat yang lebih luas (Scott dan Tilly 1975; Zinn 2000). Akan tetapi menjelang developmentalisme, keluarga inti balik bermakna positif sebagai pendukung kemajuan ekonomi (Parsons 1955; Zimmerman 1947).

Tahapan awal untuk melihat bekerjanya lembaga keluarga ialah ketiadaan pembedaan antara ruang privat dan ruang publik. Kapitalisme di Barat dikembangkan di atas pandangan impersonalitas. Berbeda dari kasus di Barat dan Jepang, kapitalisme di Indonesia terjaring dalam ikatan keluarga atau pembesaran skala ikatan keluarga.

Simpul terpenting ialah "orang yang dikenal" dan "orang tidak dikenal" (Shiraishi 2001). Simpul "orang dikenal" diturunkan dari konsep "saudara" yang sebelumnya memang bersifat cair. Orang dapat dikenal(-i) menurut etnis atau subetnis (kala berada di luar wilayah etnisnya), agama, perkawanan, hubungan perkawinan, ataupun hubungan kelahiran. Aspek psikologis penting di sini ialah keakraban. Begitu masuk ke dalam jaringan saudara, keakraban dapat disusun. 


\section{"FAMILIASI" DARI BAWAH}

Akhirnya hendak diajukan proposisi bahwa upaya pemihakan dalam suatu proses perubahan sosial dilakukan dengan menggunakan familiasi untuk menguatkan posisi dan narasi lapisan bawah dalam suatu masyarakat. Emansipasi lapisan terbawah dimungkinkan ketika suara atau narasi lapisan tersebut turut muncul dalam proses penyusunan struktur sosial

Kesadaran akan pentingnya ikatan keluarga dan kekeluargaan dalam banyak bidang di Indonesia sudah dikenal sejak masa penjajahan Hindia Belanda (Hatta 2002). Konsep ini digunakan Taman Siswa untuk mengembangkan solidaritas di antara partisipan pendidikan rakyat. Dalam bidang ekonomi, ikatan kekeluargaan ini juga digunakan pribumi untuk mengembangkan kredit dan usaha. Dapat dikatakan bahwa pada titik inilah konsep keluarga menjadi basis hibriditas bagi golongan marjinal.

Akan tetapi, keluarga dapat dimanipulasi untuk mementingkan hanya golongan elite. Dalam ranah diskursus kenegaraan, konsep kekeluargaan yang diadopsi ke dalam paham negara integralistik memungkinkan hegemoni dan eksploitasi pemerintah terhadap rakyat. Manipulasinya dalam ekonomi telah menghasilkan konglomerat dan elite yang kaya raya, namun berada di tengah "lautan" rakyat miskin.

Sampai di sini konsep familiasi dari bawah mulai disusun. Untuk mengatasi diskursus keluarga dan kekeluargaan yang menekan kelompok marjinal, keluarga dan ikatan kekeluargaan perlu dikembangkan menjadi solidaritas bersama. Ikatan imajiner ini menjadi bahan saling percaya, dan mengembangkan habitus kekuasaan. Salah satu hal yang memungkinkan ialah penemuan tokoh antarlapisan sosial, termasuk pada lapisan terbawah. Familiasi dari bawah tersusun manakala refleksi dan praksis lapisan bawah bersama agensi lain dalam penyusunan struktur desa. Untuk mengembangkan lebih lanjut, pengetahuan dapat digali melalui komparasi habituasi keluarga dan kekeluargaan dari wilayah lain di Timur.

Dari sinilah imajinasi Indonesia di masa mendatang disusun dari diskursus-diskursus "familiasi dari bawah". Dalam alam bawah sadar kita, Indonesia di masa mendatang adalah imajinasi keruangan kita semua, dan terutama bagi "saudara-saudara" kita yang berada pada tangga terbawah.

\section{DAFTAR ACUAN}

Althusser, L. 2004. Tentang Ideologi: Marxisme Strukturalis, Psikoanalisis, Cultural Studies. Terjemahan dari Essays on Ideology. Yogyakarta: Jalasutra.

Al-Fayyadl, M. 2005. Derrida. Yogyakarta: LKIS.

Anderson, BR'OG. 2002. Imagined Communities: Komunitas-komunitas Terbayang. Terjemahan dari Imagined Communities: Reflection on the Origin and Spread of Nationalism, Second Ed. Yogyakarta: Insist.

Anwar, A., S. Hadi. 1996. Perencanaan dan Pembangunan Wilayah dan Pedesaan. In: Prisma Th. 25 Edisi Khusus.

Boyne, R. 2006. Classification. In: Theory, Culture and Society Th. 23 No. 2-3.

Coleman, J. 1994. A Rational Choice Perspective on Economic Sociology. In NJ Smelser, R. Swedberg, eds. The Handbook of Economic Sociology. Princeton: Princeton Univ. Pr. 
Edelman, M, A Haugerud. 2005. "Introduction: The Anthropology of Development and Globalization" dalam The Anthropology of Development and Globalization: From Classical Political Economy to Contemporary Neoliberalism. M Edelman, A Haugerud, ed. Malden, MA: Blackwell.

Escobar, A. 1999. After Nature: Steps to Antiessentialist Political Ecology. In: Current Anthropology Th. 40 No. 1.

Escobar, A. 1996. Construction Nature: Elements for a Poststructuralist Political Ecology. In: S Jones, G Carswell, eds. 2004. The Earthscan Reader in Environment, Development and Rural Livelihoods. London, UK: Earthscan.

Escobar, A. 1992b. "Plannning”. In: W Sach, ed. The Development Dictionary: A Guide to Knowledge as Power. London: Zed Book.

Esteva, G. 1992a. “Development”. In: W Sach, ed. The Development Dictionary: A Guide to Knowledge as Power. London: Zed Book.

Derrida, J. 2005. Kosmopolitanisme E Forgiveness. Terjemahan dari Cospolitanism and Forgiveness. Yogyakarta: Alinea.

Durkheim, E. 1933. The Division of Labor in Society. New York: Free Press.

Fernando, JL. 2003. The Power of Unsustainable Development: What Is to Be Done? In: ANNALS No. 590 .

Foucault, M. 2002a. Pengetahuan dan Metode: Karya-karya Penting Foucault. Terjemahan dari P Rabinow, ed. Aesthetics, Method and Epistemology: Essential Works of Foucault 19541984. Yogyakarta: Jalasutra

Foucault, M. 2002b. Power/Knowledge: Wacana Kuasa/Pengetahuan. Terjemahan. Yogyakarta: Bentang.

Hatta, M. 2002. Pengantar ke Jalan Sosiologi Ekonomi. Jakarta: Gunung Agung.

Hefner, RW. 2000. Islam Pasar Keadilan: Artikulasi Lokal, Kapitalisme, dan Demokrasi. Yogyakarta: LKiS.

Heryanto, A. 2000. Perlawanan dalam Kepatuhan: Esai-esai Budaya. Bandung: Mizan.

Irwan, A. (2005). "Institutions, Discourses, and Conflicts in Economic Thought". In: VR Hadiz, D Dhakidae, eds. Social Change and Power in Indonesia. Singapore: Equinox dan ISEAS.

Malarangeng, R. 2002. Mendobrak Sentralisme Ekonomi: Indonesia 1986 - 1992. Jakarta: KPG.

Nordholt, NS. 1987. Ojo Dumeh: Kepemimpinan Lokal dalam Pembangunan. Jakarta: Sinar Harapan.

Onghokham. 1986. Korupsi dan Pengawasan dalam Perspektif Sejarah. In: Prisma Th. 15 No. 3.

Parsons, T. 1955. "The Isolated Conjugal Family" dalam Sociology of the Family, ed. ke-2. M. Anderson. Middlesex, UK: Penguin.

Robbins, P. 2004. Political Ecology. Malden, MA: Blackwell.

Said, E. W. 2001. Orientalisme. Terjemahan Orientalism. Bandung: Pustaka.

Said, E. W. 1995. Kebudayaan dan Kekuasaan: Membongkar Mitos Hegemoni Barat. Terjemahan. Bandung: Mizan.

Sajogyo. 2006. Ekososiologi: Deideologisasi Teori, Restrukturisasi Aksi (Petani dan Perdesaan sebagai Kasus Uji). Yogyakarta: Cindelaras.

Scott, JW, LA Tilly. 1975. "Women's Worlk and the Family in Nineteenth-Century" dalam Sociology of the Family. ed. ke-2. M. Anderson. Middlesex, UK: Penguin.

Shiraishi, SS. 2001. Pahlawan-pahlawan Belia: Keluarga Indonesia dalam Politik. Terjemahan dari Young Heroes: Indonesian Family in Politics. Jakarta: Kepustakaan Populer Gramedia.

Soemardjan, S. 1991. Perubahan Sosial di Yogyakarta. Yogyakarta: Gadjah Mada Univ. Pr.

Venn, C. 2006. The Postcolonial Challenge: Towards Alternative Worlds. London: Sage.

Zimmerman, CC. 1947. "The Atomistic Family" dalam Sociology of the Family. ed. ke-2. M. Anderson. Middlesex, UK: Penguin.

Zinn, MB. 2000. "Feminism and Family Studies for a New Century". In: ANNALS, AAPSS No. 571. 